This PDF is a selection from a published volume from the National Bureau of Economic Research

Volume Title: Investigations in the Economics of Aging

Volume Author/Editor: David A. Wise, editor

Volume Publisher: University of Chicago Press

Volume ISBN: 0-226-90313-3; 978-226-90313-2 (cloth)

Volume URL: http://www.nber.org/books/wise11-2

Conference Date: May 5-8, 2011

Publication Date: May 2012

Chapter Title: How Well Are Social Security Recipients Protected from Inflation?

Chapter Authors: Gopi Shah Goda, John B. Shoven, Sita Nataraj Slavov

Chapter URL: http://www.nber.org/chapters/c12433

Chapter pages in book: (p. 119 - 139) 


\title{
How Well Are Social Security Recipients Protected from Inflation?
}

\author{
Gopi Shah Goda, John B. Shoven, and \\ Sita Nataraj Slavov
}

\subsection{Introduction}

Social Security is widely believed to protect its recipients from a number of risks, including uncertainty regarding length of life and inflation, due to the inflation-indexed life annuity form of the benefit. The inflation protection comes from the fact that Social Security benefits are indexed to the Consumer Price Index for Urban Wage Earners and Clerical Workers (CPI-W). The CPI-W is based on the spending patterns of a broad group of workers, representing approximately 32 percent of the US population. However, the CPI-W may not accurately reflect the experience of retirees for two reasons. First, retirees generally have higher medical expenses than workers, and medical costs in recent years have tended to rise faster than the prices of other goods. Second, even if medical costs did not rise faster than

Gopi Shah Goda is research scholar and postdoctoral fellow program coordinator at the Stanford Institute for Economic Policy Research, Stanford University, and a faculty research fellow of the National Bureau of Economic Research. John B. Shoven is the Charles R. Schwab Professor of Economics at Stanford University and a research associate of the National Bureau of Economic Research. Sita Nataraj Slavov is associate professor of economics at Occidental College.

This research was supported by the US Social Security Administration (SSA) through grant \#10-M-98363-1-01 to the National Bureau of Economic Research as part of the SSA Retirement Research Consortium. The findings and conclusions expressed are solely those of the authors and do not represent the views of the SSA, any agency of the federal government, or the NBER. The authors would like to thank Isabella Tang for superb research assistance. For acknowledgments, sources of research support, and disclosure of the authors' material financial relationships, if any, please see http://www.nber.org/chapters/c12433.ack. This paper was previously published as Gopi Shah Goda, John B. Shoven, and Sita Nataraj Slavov (2011), "How Well Are Social Security Recipients Protected from Inflation?," National Tax Journal 64 (2): 429-49. Permission to reprint this article was granted by the National Tax Association. 
the prices of other goods, individual retirees would still, on average, need to devote a larger share of income to medical spending as they age. This means that individual retirees would still see a decline in the real income they have available for nonmedical spending. In this chapter, we explore both of these factors, quantify the extent to which they undermine the inflation protection provided by the indexation of Social Security benefits, and explore the implications of alternative methods of indexing benefits.

Our analysis is related to the literature on cost-of-living indices for the elderly. Most recently, Burdick and Fisher (2007) and Stewart (2008) compare the CPI-W to the CPI-E, an experimental consumer price index based on the spending patterns of the elderly, produced but not published by the Bureau of Labor Statistics (BLS). Since the CPI-E is intended to reflect the experience of Americans aged sixty-two and older, the main difference between the CPI-E and the CPI-W is in the weights for the various expenditure categories. The CPI-E has increased faster than the CPI-W over the past twenty years, due primarily to the relative rise in health care costs, and the fact that the elderly spend more on health care than the nonelderly, even after taking into account the availability of Medicare. Hobijn and Lagakos (2003) suggest that if Social Security benefits were indexed to the CPI-E instead of the CPI-W, the Trust Fund depletion date would be moved forward by about five years. This result demonstrates that there are important differences between the two indices, and that the choice between them is consequential. Other relevant research includes Boskin and Hurd (1982), who compute separate price indices for elderly and nonelderly households even before the CPI-E was constructed, and List (2005), who reviews the issues regarding cost-of-living indices for the elderly, but without as much of a focus on health care spending.

In carrying out our analysis, we examine two major components of medical costs. First, most Social Security recipients are also participants in Medicare Part B. The monthly premiums for Part B, which recently became means-tested, go up with the increasing costs of health insurance as they account for approximately 25 percent of the cost of providing benefits. These premiums are automatically deducted from Social Security retirement benefits and have increased much faster than Social Security benefits. The dramatic difference in growth rates is shown in figure 3.1, which illustrates that the monthly premium of Part B has gone up approximately 1,600 percent between 1975 and 2011 (i.e., the amount is seventeen times higher than it was), while the automatic cost-of-living adjustments have accumulated to just over 300 percent. Moreover, with means-adjusted Part B premiums introduced in 2007, very high-income individuals (with modified adjusted gross income of more than $\$ 214,000$ in 2011) saw their Medicare Part B monthly premiums go from $\$ 45.50$ in 2000 to $\$ 369.10$ in 2011 . The increase for these very high-income people clearly eroded the real value of their 


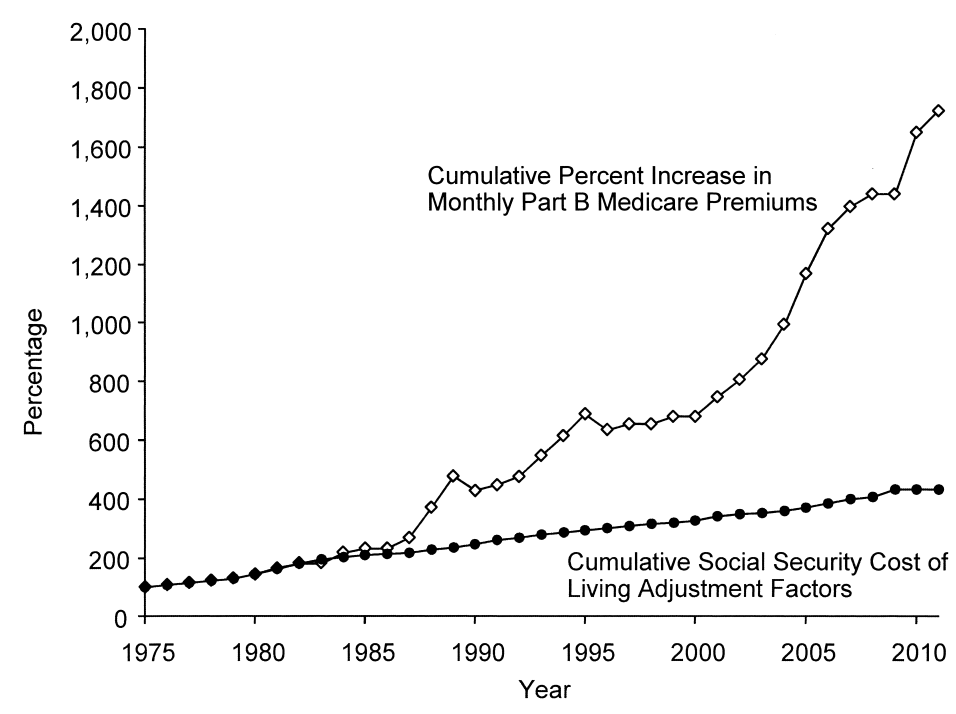

Fig. 3.1 Cumulative percent increase in Medicare Part B premiums and Social Security cost-of-living adjustment factors, 1965-2011

Note: Medicare Part B premiums and cost-of-living adjustment normalized to 100 in 1975.

monthly Social Security benefit. Second, retirees often have substantial out-of-pocket medical expenses, including Medicare deductibles and copayments, and payments for services with limited Medicare coverage, such as nursing home care.

We show that, after subtracting both of these components of health spending from Social Security benefits, available income net of medical expenses for a Social Security participant with average out-of-pocket medical spending has, in fact, been increasing more slowly than a price index of nonmedical goods and services. For example, the average man born in 1918 has seen his monthly Social Security benefit, net of medical expenses, rise from $\$ 527.85$ at the end of 1983 (when he was sixty-five) to $\$ 866.80$ at the end of 2007 (when he was eighty-nine). However, if his net-of-medical-expenses benefit had kept pace with inflation in the prices of nonmedical goods over that time period, he would have had $\$ 1,086.13$ per month in 2007 after medical expenses. That is, his net-of-medical-spending benefit has declined by around 20 percent, relative to the nonmedical goods price index. Similarly, the average woman born in 1918 has seen her net-of-medical-expenses benefit decline by around 27 percent relative to the nonmedical goods price index. Of course, these results assume no other income besides Social Security, but a sizable fraction of the elderly depend on Social Security for the majority of their income: 64 percent of beneficiaries rely on Social Security 
for 50 percent or more of their income, and 34 percent of beneficiaries rely on Social Security for 90 percent or more of their income. ${ }^{1}$

We also show that if Social Security benefits had been indexed to the CPI-E instead of the CPI-W, men born in 1918 would have $\$ 961.20$ net of medical expenses, falling only 11.5 percent short of the $\$ 1,086.13$ needed to hold nonmedical expenditures constant in real terms; similarly, women born in 1918 would fall only 18.1 percent short. The reason indexing to the CPI-E does not fully compensate retirees for inflation is that, even if medical costs remained constant over time for the elderly, they tend to spend more on out-of-pocket medical expenses as they age, crowding out nonmedical spending. Thus, each cohort's Social Security benefit net of average outof-pocket medical spending would tend to decline in real terms even if the price of medical care rose at the same rate as the prices of other goods, or alternatively, even if the average retiree's real net Social Security benefit remained constant.

Both the CPI-W and CPI-E are subject to the usual criticisms of consumer price indices. In particular, neither accounts adequately for technological progress or for consumer substitution among goods. The CPI-E is subject to additional criticisms, including the fact that it overlooks senior citizen discounts and differences in the retail shopping patterns of the elderly, and is based on a relatively small sample. ${ }^{2}$ The failure to account properly for technological progress can be quite serious when it comes to health care. Higher medical costs may reflect the consumption of better quality medical care, and retirees may be better off even if they are left with less to spend on other nonmedical goods. Therefore, we emphasize that we cannot draw any conclusions about changes in the utility of Social Security recipients from this analysis. All we show is that Social Security benefits may not be fully inflation-indexed in the sense that recipients with average out-of-pocket medical spending cannot, from one year to the next, purchase the same bundle of nonmedical goods with their Social Security benefits.

Our methodology and results are described in more detail in sections 3.2 and 3.3. Section 3.4 discusses the policy implications of changing the method of indexation, and section 3.5 offers concluding remarks.

\subsection{Methodology}

Our analysis proceeds in several steps. First, we estimate a model to predict average out-of-pocket medical spending as a function of age, gender, and race. Second, we estimate average Social Security benefits broken down by age, gender, and race. Third, we subtract Medicare Part B premiums, as

1. US Social Security Administration, Office of Retirement and Disability Policy, "Fast Facts and Figures About Social Security," http://www.ssa.gov/policy/docs/chartbooks/fast_ facts/2010/fast_facts $10 . h t m l$.

2. See Stewart (2008) and Budrick and Fisher (2007) for a more detailed discussion. 
well as our estimates of average out-of-pocket medical expenses, from these average benefits. Finally, we compare the rate of increase in the remaining amount (nonmedical spending) to the CPI-E for all items less medical expenses. Each of these steps is detailed in the following subsections.

\subsubsection{Out-of-Pocket Spending}

We use Health and Retirement Study (HRS) data from 1995, 1996, 1998, 2000, 2002, 2004, and 2006 to model the age profile of out-of-pocket medical expenses. ${ }^{3}$ Our analysis is limited to these years because the definition of out-of-pocket expenses is relatively consistent across interviews starting in 1995. The sample includes all individuals aged sixty-five to eighty-nine. The HRS collects data on a wide range of out-of-pocket medical expenses, including payments for doctor and dentist visits, hospital and nursing home stays, outpatient surgery, prescription drugs, home health care, and special facilities. Respondents are asked about their total out-of-pocket spending over the two years prior to the interview; we divide this amount by twenty-four to arrive at monthly out-of-pocket spending. One shortcoming of the HRS data is that it does not include health insurance premiums in out-of-pocket medical expenses, including those for Medicare Part B. Later in the analysis, we add Part B premiums to predicted out-of-pocket expenditures.

We regress monthly total out-of-pocket spending (the sum of all the components just listed) on a variety of demographic variables, including age, age-squared, gender, and race (white non-Hispanic, black non-Hispanic, or other race). The results from our three basic specifications are shown in table 3.1. ${ }^{4}$ Specification 1 does not include any controls for race, but allows the level and shape of the age profile of spending to vary by gender by including a gender dummy interacted with the age variables. Specification 2 adds race dummies, allowing the level, but not the shape, of the age profile to vary by race. Specification 3 includes a full set of interactions among race, age, and gender, allowing each race-gender combination to have a different level and shape. All specifications include a set of year dummies, which allow the age profiles to shift (generally upwards) over time.

We use specification 1 to construct a preliminary age profile of out-ofpocket spending for men and women aged sixty-five to eighty-four in each year from 1983 to 2007. Predicted values for years not covered by our HRS data are assigned the intercept for the closest year in the HRS; for example,

3. University of Michigan, Institute for Social Research, Health and Retirement Study, http://hrsonline.isr.umich.edu/.

4. Other studies use the log of medical expenses as the dependent variable (e.g., French and Jones 2004). Although we also estimated regressions using the log of out-of-pocket spending as our dependent variable, we prefer the linear specifications because, when aggregated, they produce results that most closely match the actual aggregate values of out-of-pocket spending. The semi-log regression results are available from the authors upon request. 
Table 3.1

Predicting out-of-pocket medical spending

\begin{tabular}{lccc}
\hline Specification & $(1)$ & $(2)$ & $(3)$ \\
\hline Age & $-20.4^{*}$ & $-21.5^{*}$ & $-22.3^{*}$ \\
& $(11.3)$ & $(11.3)$ & $(12.6)$ \\
Age-squared & $.155^{* *}$ & $.161^{* *}$ & $.169^{* *}$ \\
& $(.074)$ & $(.0739)$ & $(.0824)$ \\
Female & $1,500^{* * *}$ & $1,568^{* * *}$ & $2,236^{* * *}$ \\
& $(557)$ & $(557)$ & $(627)$ \\
Female*Age & $-40.4^{* * *}$ & $-42.1^{* * *}$ & $-60^{* * *}$ \\
& $(14.6)$ & $(14.6)$ & $(16.5)$ \\
Female*Age- & $.273^{* * *}$ & $.284^{* * *}$ & $.404^{* * *}$ \\
squared & $(.0956)$ & $(.0955)$ & $(.107)$ \\
& & $-40.4^{* * *}$ & -280 \\
Black & & $(6.01)$ & $(1,341)$ \\
& & $-61.1^{* * *}$ & -700 \\
Other race & & $(7.08)$ & $(1,592)$ \\
Interactions & $\mathrm{No}$ & $\mathrm{No}$ & Yes \\
$R^{2}$ & 0.011 & 0.013 & 0.014 \\
\hline
\end{tabular}

Notes: All specifications include year dummies. Standard errors are in parentheses. Specification 3 also includes all three-way interaction terms between age, gender, and race. The number of observation is $N=58,004$.

***Significant at the 1 percent level.

**Significant at the 5 percent level.

*Significant at the 10 percent level.

1985 is given the intercept for 1995 (the earliest year in our HRS sample), and 1997 is given the intercept for 1996. Clearly we would expect our predicted profiles to be more accurate for the years covered by the HRS data. However, as long as the predicted relative values of spending for the age-gender groups are accurate, we can scale the levels to match the overall level of out-of-pocket expenditures. We do this by aggregating our predicted values using population counts for men and women of each age group, and then dividing actual aggregate expenditures for the sixty-five to eighty-four age group in each year by our predicted aggregate expenditures. ${ }^{5}$ These ratios of actual to predicted aggregate expenditures are our "scaling factors." We then multiply our preliminary predicted age profiles by the scaling factor for the appropriate year. Figure 3.2 shows the predicted and actual aggregate expenditures for the sixty-five to eighty-four age group, as well as the scaling

5. Population counts were obtained by request from the Social Security Administration, and actual aggregate expenditures from the Centers for Medicare and Medicaid Services, National Health Expenditure Data, https://www.cms.gov/NationalHealthExpendData/. Aggregate outof-pocket expenditures by age are reported for years 1987, 1996, 1999, 2002, and 2004. To impute out-of-pocket expenditures for additional years, the 2004 values were adjusted by the rate of growth of aggregate out-of-pocket payments for all ages. This procedure yielded values that closely match the actual values in the years where expenditures by age were reported. 


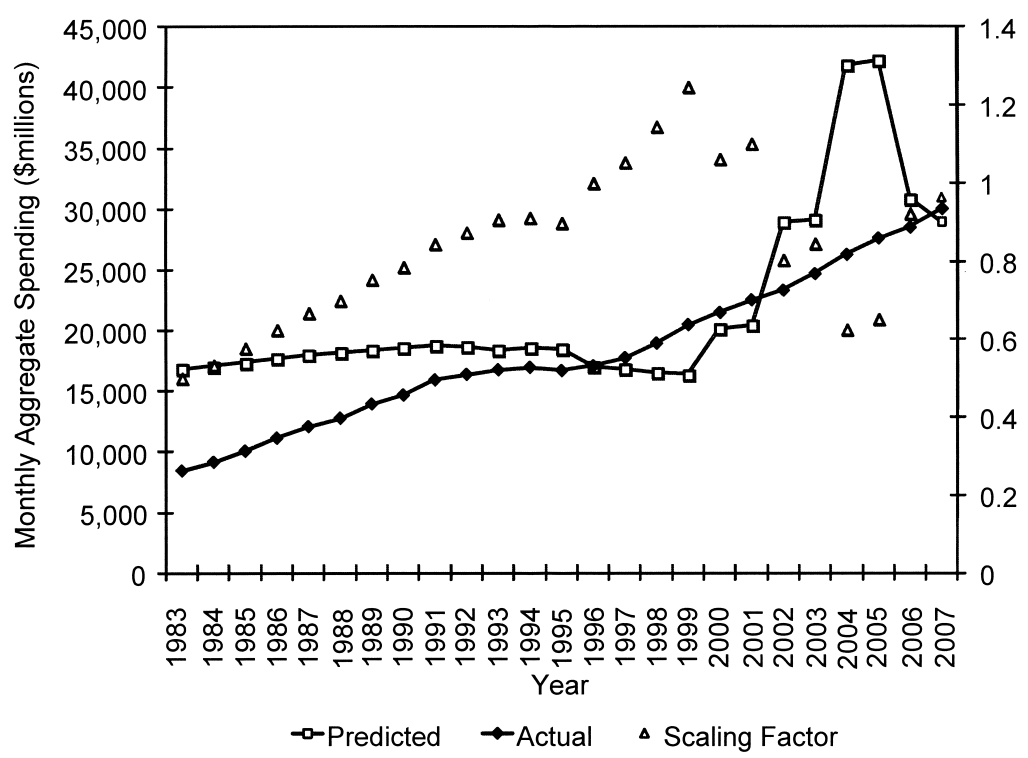

Fig. 3.2 Actual and predicted aggregate out-of-pocket medical spending, ages 65-84

factors for each year. The scaling factors are quite close to 1 for most of the years covered by the HRS data.

For example, actual aggregate expenditures in 2006 were 1.06 times the aggregate amount predicted by our regression model for 2006. Our model also predicts that a seventy-year-old male has average out-of-pocket expenses of $\$ 125.64$ per month in 2006 . We multiply this amount by the scaling factor of 1.06 to obtain $\$ 133.21$, our final predicted value for average out-of-pocket expenditures of seventy-year-old males in 2006. Thus, we construct our age profiles by using our regression to predict the relative values of average out-of-pocket expenditures for the age-gender groups, and then choosing the levels to match actual aggregate expenditures in the sixty-five to eighty-four age group.

We repeat this procedure for specification 3 to obtain the age profiles of out-of-pocket spending for four groups: white males, white females, black males, and black females. ${ }^{6}$ For the breakdown by race, we chose specification 3 rather than 2 because there appear to be substantial differences in the

6. The procedure is identical to that for specification 1, except that we scale our model's predicted out-of-pocket expenditures to match aggregate expenditures for individuals aged sixty-five to seventy-four. This is because our population counts by race, gender, and age come from the Current Population Survey, http://www.census.gov/cps/, in which age is top-coded at eighty for many years in our sample period. As we cannot know whether an individual with a top-coded age is younger than eighty-five, we cannot use the aggregate amounts for the sixtyfive to eighty-four age group. 
shapes of the age profiles across races, and the interactions are jointly significant at the 1 percent level. Our results - the scaled, predicted age profilesare presented and discussed in the next section.

\subsubsection{Social Security Benefits}

The Social Security Administration's Statistical Supplement for 2008, http://www.ssa.gov/policy/docs/statcomps/supplement/2008/index.html, contains data on the average Social Security benefit received by retired workers in December 2007, broken down by race, gender, and single year of age. We include retired worker benefits only, not disability, survivor, or spouse benefits. We then use the CPI-W to "backtrack" these average benefits to the year in which the group was aged sixty-five. That is, the benefit for a group aged $i$ in 2007 in any year $t \geq 2007-i$ is

$$
B_{t}^{i}=\frac{B_{2007}^{i}}{\prod_{s=t}^{2006}\left(1+\mathrm{COLA}_{s}\right)},
$$

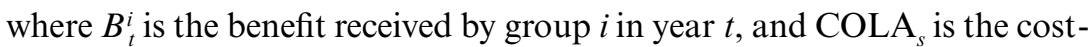
of-living adjustment, or the percentage by which the benefit in year $s$ is increased to arrive at the benefit in year $s+1$. These amounts are taken to represent what the individuals who are currently in group $i$ would have received in previous years.

Clearly, there is a potential for sample selection bias. Our analysis for each cohort is based on individuals who survived until 2007. There is evidence to suggest that there are substantial differentials in mortality rates across income groups (Waldron 2007; Cristia 2007). Thus, the individuals in our sample are likely to be among the higher earners in their cohort, who are receiving above-average Social Security benefits. This effect is more likely to be important for older cohorts. Additionally, not all of the individuals in the 2007 groups would have started receiving benefits at age sixty-five; some may have delayed until age seventy and received a credit. A final issue is that, by assuming that the benefit received in 2007 is the benefit received at retirement plus the subsequent COLAs, we do not account for individuals who may have switched from receiving a retirement benefit to receiving a survivor's benefit upon the death of a spouse. It is possible that a retiree who experienced the death of a spouse might have switched to receiving a survivor's benefit (two-thirds of the deceased spouse's primary insurance amount) if the survivor's benefit was larger than the initial worker-only benefit. While these three factors affect the level of benefits we use as our benchmark, they do not affect our main conclusions of the relative differences in benefits from different types of benefit indexation policies.

\subsubsection{Net-of-Medical-Expense Benefits}

From the average benefits by race, age, and gender, we subtract the premiums paid for Medicare Part B and our predicted out-of-pocket spending on 
medical care for the relevant age-race-gender group. Medicare Part B premiums are automatically deducted from Social Security payments for those Medicare beneficiaries who do not opt out of Part B (inpatient insurance). This includes the vast majority of Medicare beneficiaries. We ignore the means testing for Part B that became effective in 2007 and assume everyone pays the standard Part B premium, a reasonable assumption given our focus on individuals who depend primarily on Social Security for their retirement income. ${ }^{7}$ This allows us to track the growth of nominal benefits net of average out-of-pocket medical expenses over time for each cohort within a race-gender group. We compare this to the growth in the CPI-E for all items less medical expenses. ${ }^{8}$ The CPI-E net of medical expenses tells us what our groups would need for nonmedical expenses at the end of 2007 in order to have the same purchasing power as they did when they were age sixty-five. Additionally, we compute the path of each group's Social Security benefit, starting at age sixty-five, if benefits had been indexed to the CPI-E instead of the CPI-W. This tells us the extent to which indexation to the CPI-E would have protected retirees from inflation. ${ }^{9}$

\subsection{Results}

\subsubsection{Predicted Out-of-Pocket Expenses}

Figures 3.3 and 3.4 show our simulated average out-of-pocket medical spending for all men and all women. Figures 3.5 through 3.8 show simulated average out-of-pocket medical spending for black men, black women, white men, and white women separately. The two solid lines represent the age profiles of spending in 1987 and 2007. However, as a particular cohort ages, it moves from the curve for one year to the curve for the next year. Therefore, the age profile for a particular cohort is steeper than the age profile across

7. Means testing was in effect in 2007 for individuals with a modified adjusted gross income over $\$ 80,000$.

8. We are grateful to Ken Stewart of the BLS for providing us with unpublished CPI-E data. We have the CPI-E for all items less medical care for 1987 to 2007. We estimate the values for 1983 to 1986 as follows. Using the weights for medical care in the CPI-E for 1987, 2007, and 2008 (the BLS did not retain historical weights for other years), we fit a quadratic equation through these three values (with year as the independent variable), and use this equation to predict the weights for the other years. Using the fitted weights, we solve for the growth rate of the CPI-E for all items less medical care in the formula $g_{t}=w_{t-1} g_{t}^{m}+\left(1-w_{t-1}\right) g_{t}^{n m}$, where $g_{t}$ is the growth in the CPI-E from year $t-1$ to year $t, g_{t}^{m}$ is the growth in the CPI-E for medical care from year $t-1$ to year $t, g_{t}^{n m}$ is the growth in the CPI-E for all items less medical care from year $t-1$ to year $t$, and $w_{t-1}$ is the weight on medical care in year $t-1$. Using the same procedure for the CPI-W yields estimates of the CPI-W for all items less medical care that are fairly close to the actual values.

9. The COLAs applied by the SSA are based on the change in the CPI-W from the third quarter (Q3) of the previous year and Q3 of the current year. For the CPI-E, we only have the December-to-December (rather than the Q3-to-Q3) changes; therefore, all our analysis using the CPI-E uses December-to-December changes. While these may vary from the Q3-to-Q3 changes for particular years, the cumulative effect over the years should be approximately the same. 


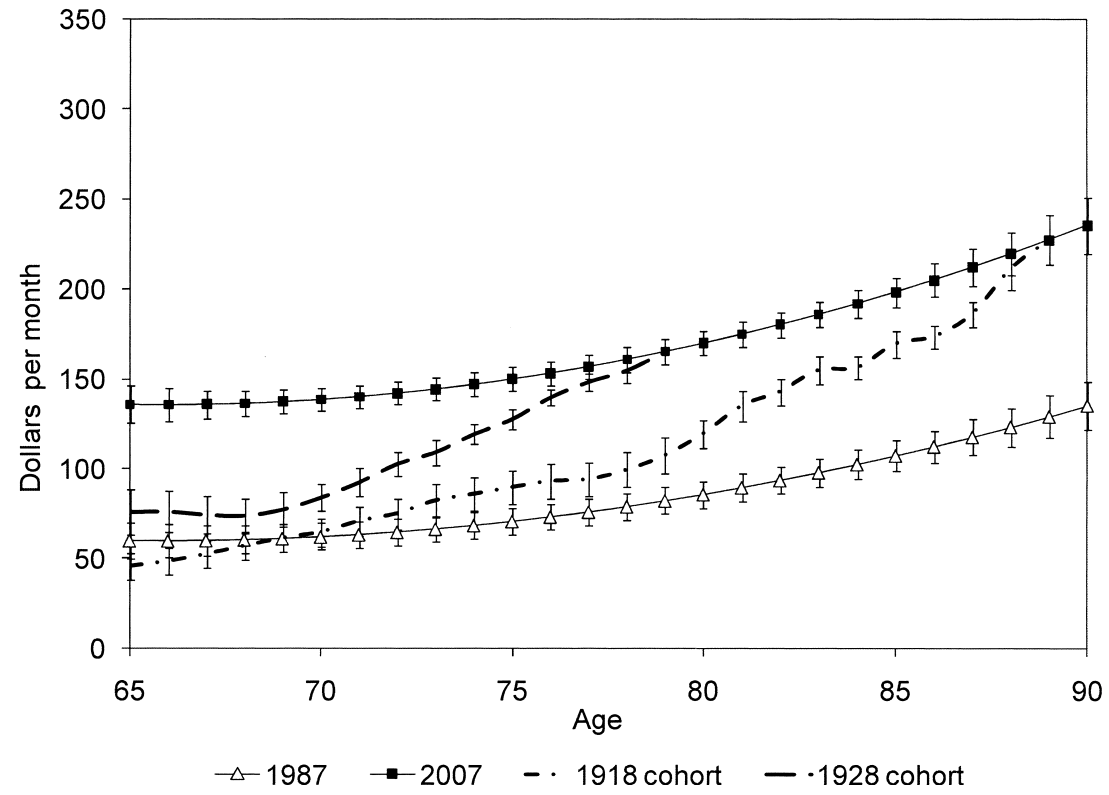

Fig. 3.3 Simulated out-of-pocket medical spending by year and age, all males

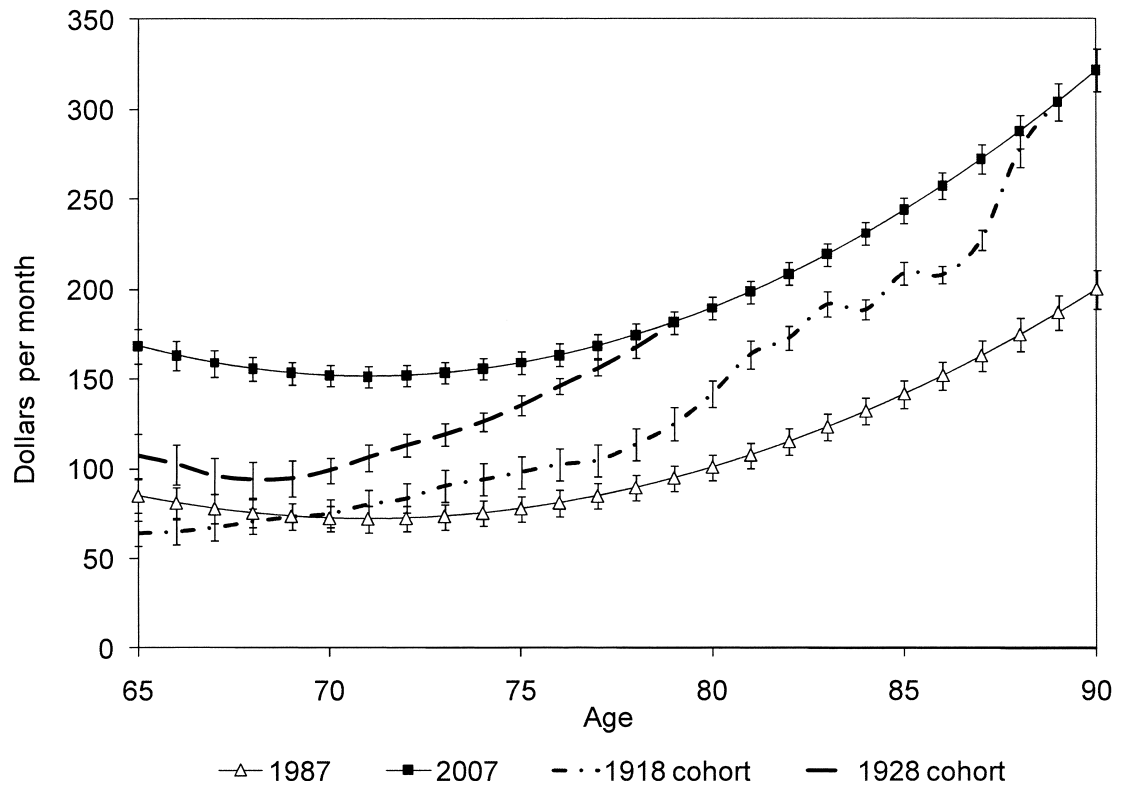

Fig. 3.4 Simulated out-of-pocket medical spending by year and age, all females 


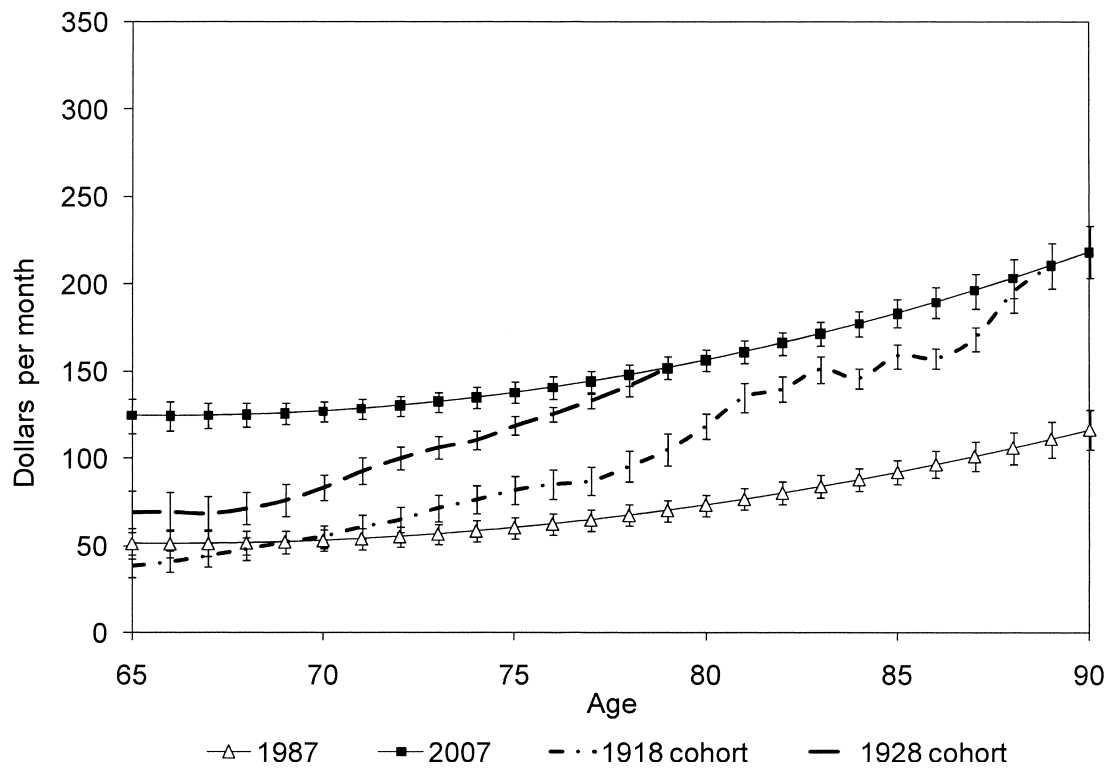

Fig. 3.5 Simulated out-of-pocket medical spending by year and age, white males

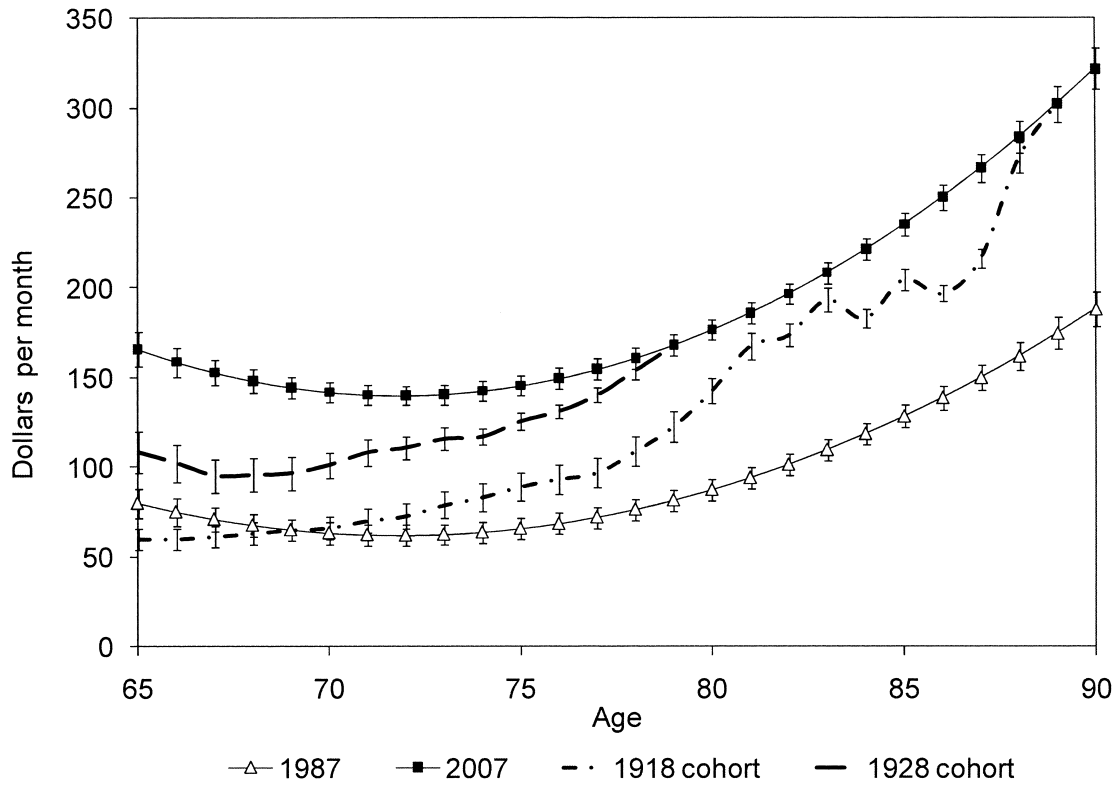

Fig. 3.6 Simulated out-of-pocket medical spending by year and age, white females 


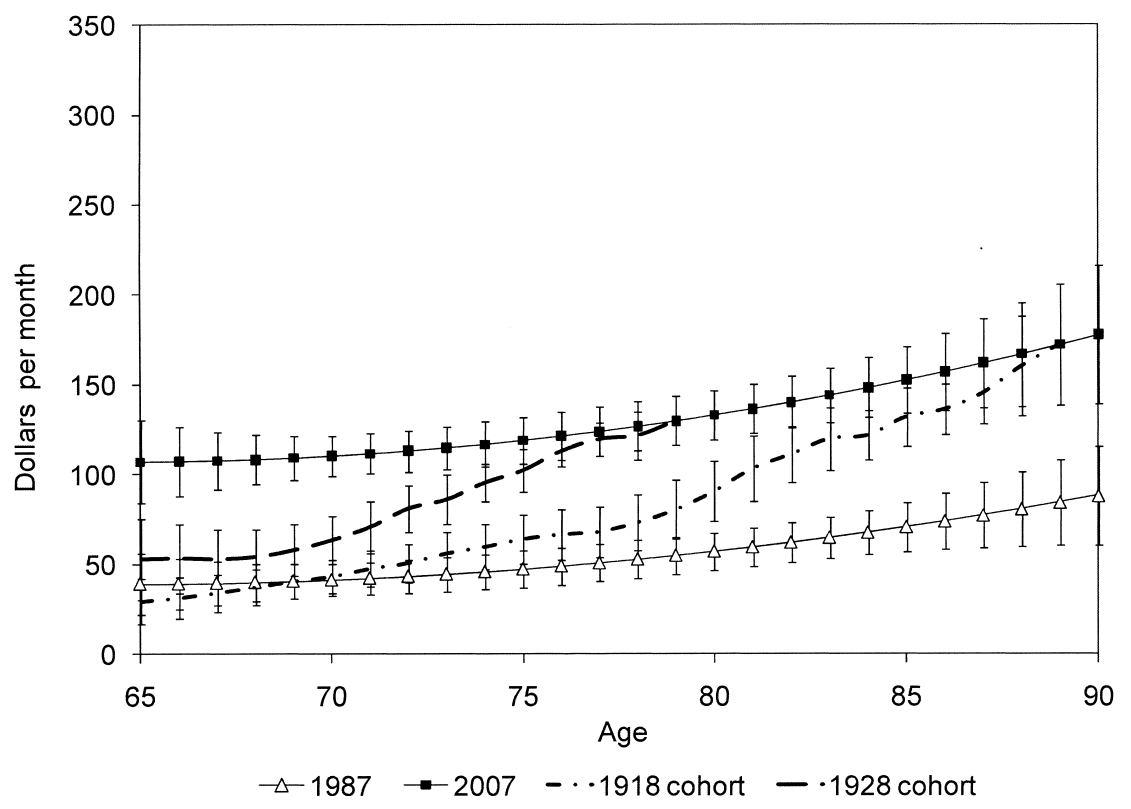

Fig. 3.7 Simulated out-of-pocket medical spending by year and age, black males

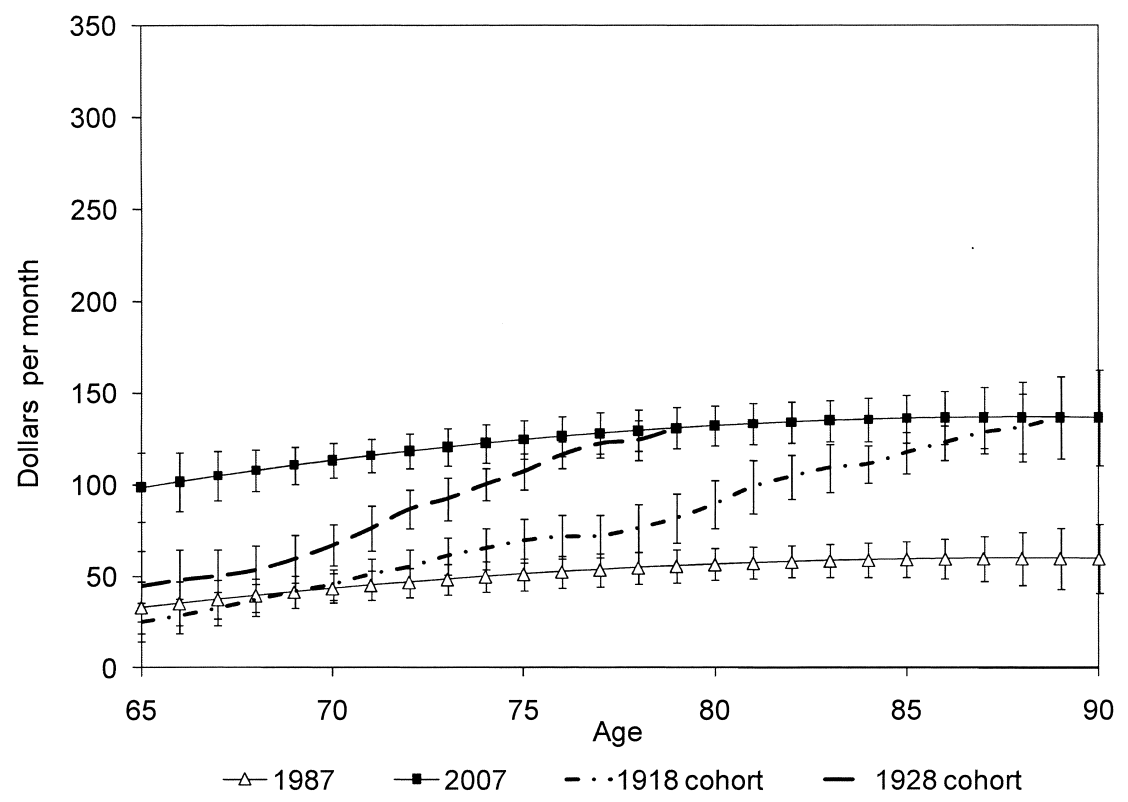

Fig. 3.8 Simulated out-of-pocket medical spending by year and age, black females 
cohorts in a given year. The average out-of-pocket medical spending of the cohorts born in 1918 and 1928 are depicted by the dashed lines. The vertical bars represent the standard errors of our predicted values. ${ }^{10}$

Overall, average out-of-pocket expenses are higher - and rise faster-for women than for men. This result is consistent with other studies of medical expenditures (French and Jones 2004; Di Nardi, French, and Jones 2009). Di Nardi, French, and Jones (2009) show that, after controlling for age, income, and health status, men spend about 20 percent less than women on medical care. Our results suggest that this relationship appears to be driven primarily by white men and women; black women tend to have a lower and flatter profile of expenses than black men.

It is not clear why women overall seem to have higher and steeper expense profiles than men. One possibility is that, because women tend to outlive men and husbands tend to be older than their wives, there are more elderly widows than widowers. Older retirees living alone may have higher out-ofpocket medical expenses because, to some extent, a spouse can substitute for paid caregivers. In our 2006 sample, 56 percent of men aged eightyfive and above are married, compared to only 17 percent of women in the same age group. Men aged eighty-five and above had mean out-of-pocket medical expenses of \$197 per month, compared with \$276 per month for women in the same age group. However, married women aged eighty-five and above had monthly expenses of only $\$ 181$, compared to $\$ 295$ for single women. Single men's expenses were only slightly higher than those of married men - \$198 versus $\$ 196$ per month. ${ }^{11}$ This provides some support for the hypothesis that differences in marital status can partly explain the observed gender differences.

One possible explanation for the flatness of the profiles for African Americans relative to whites is that elderly African Americans tend to have lower incomes than elderly whites. Current Population Survey data, http://www .census.gov/cps/, suggest that 7.9 percent of whites aged sixty-five and older are living in poverty, in comparison to 22.7 percent of African Americans aged sixty-five and older. Thus, elderly whites are more likely to have income and assets that can be used to finance high medical expenses. Indeed, Di Nardi, French, and Jones (2009) show that the age profile of medical expenses is much steeper for higher-income individuals, with differences in spending across income groups becoming far more pronounced at older

10. We assume that the standard error of the adjusted prediction is equal to the scaling factor multiplied by the standard error of the original prediction.

11. For this calculation, married is defined as either married with a spouse present, or partnered. Single is defined as married with an absent spouse, separated, divorced, widowed, or never married. We classify individuals who are married with an absent spouse as single because we are trying to capture the impact of living alone. There are 410 men and 768 women aged eighty-five and above in the 2006 sample. 
ages. For individuals in their mid-seventies, medical expenses do not vary much with income; however, at age 100, individuals in the top quintile of lifetime income spend more than ten times as much as individuals in the bottom quintile.

We also note that our simulations of average out-of-pocket medical spending mask a large amount of variation in actual out-of-pocket medical spending experienced by the elderly. For example, French and Jones (2004) show that individuals face considerable risk of catastrophic health costs. Our regression results show that only a small part of the variation in out-of-pocket medical spending is explained by age, gender, and race. The level of out-of-pocket medical expenditures for any one individual may vary greatly from our predictions, and any given individual is also likely to experience more variation from year to year than our averages by race, gender, and age suggest.

\subsubsection{Benefits Net of Average Out-of-Pocket Medical Expenses}

To summarize our results, we focus on the experience of two cohortsindividuals born in 1918, and individuals born in 1928. The former cohort is eighty-nine at the end of 2007, and the latter is seventy-nine at the end of 2007.

Figures 3.9 and 3.10 depict the experience of the 1918 cohort of men

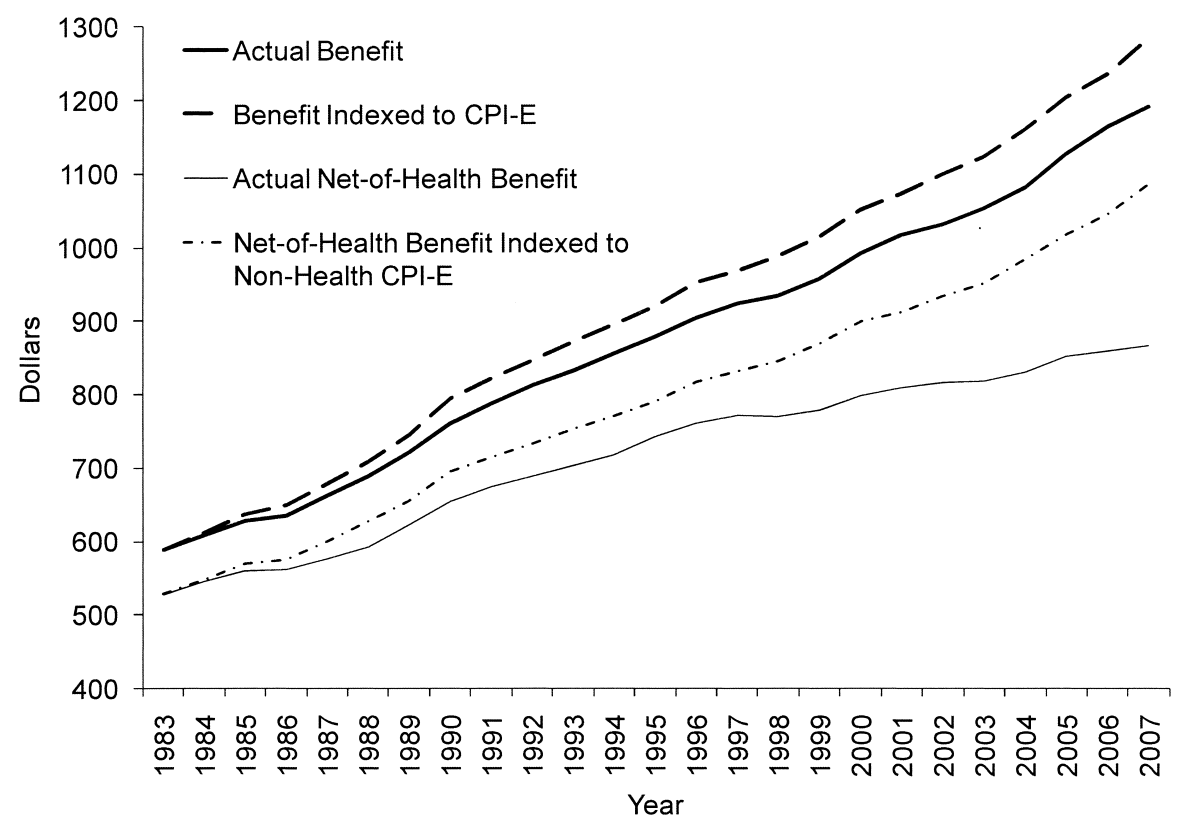

Fig. 3.9 Difference in monthly benefits using CPI-W and CPI-E, men aged 89 in December 2007 


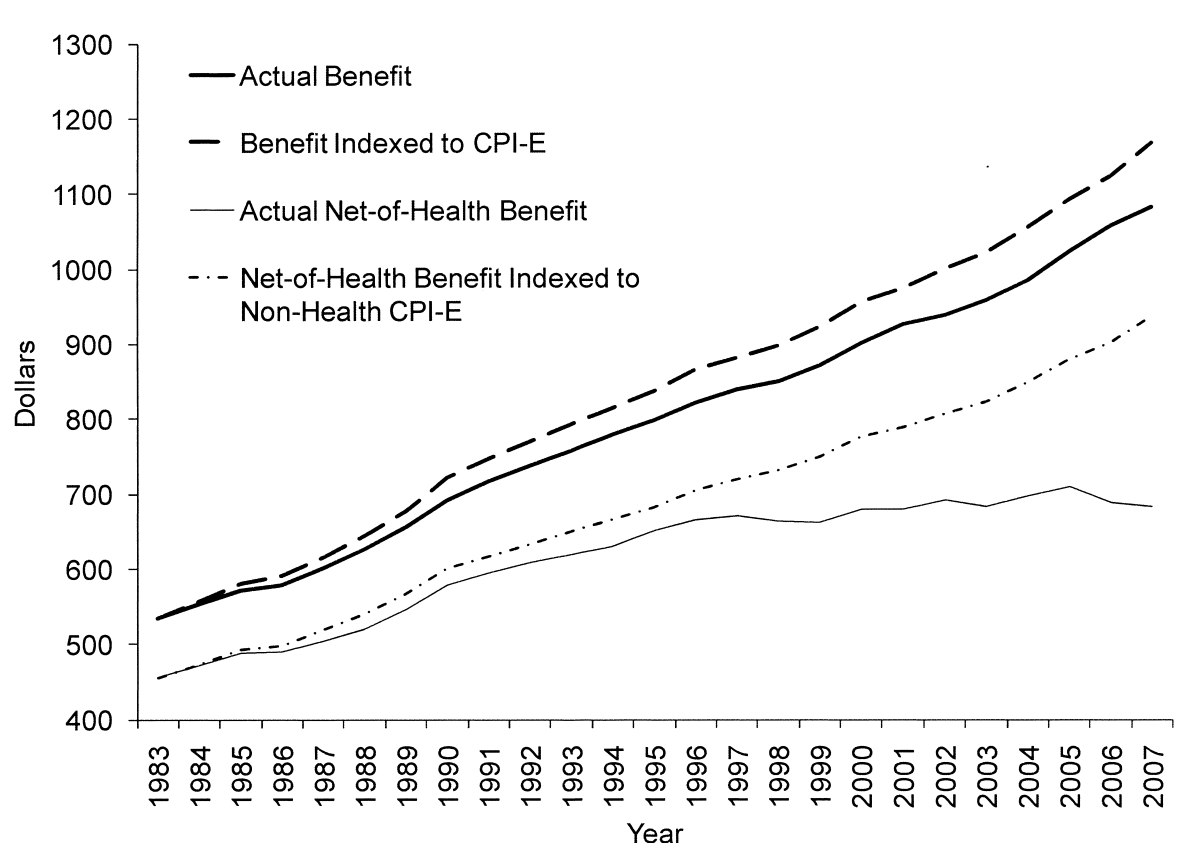

Fig. 3.10 Difference in monthly benefits using CPI-W and CPI-E, women aged 89 in December 2007

and women. In each graph, the solid black line shows the evolution of the cohort's actual Social Security benefit. The dashed black line shows the evolution of the cohort's Social Security benefit if the benefit had been indexed to the CPI-E. The solid gray line shows the actual benefit net of average outof-pocket medical spending received by the cohort. Finally, the dashed gray line shows the benefit net of average out-of-pocket medical spending that would be required to keep pace with inflation in the prices of nonmedical goods (as measured by the CPI-E for all goods less medical care).

These graphs suggest that benefits net of average out-of-pocket medical spending have risen more slowly than the price index for nonhealth spending. The same pattern emerges for the four race-gender groups (the graphs are not shown), and for the 1928 birth cohort. The results for these other groups are summarized in table 3.2. The second column of the table shows, for each group, the actual monthly benefit net of average out-of-pocket medical expenses at age 65 . The third column shows the actual monthly benefit net of average out-of-pocket medical expenses in December 2007. The third column shows the monthly benefit net of average out-of-pocket medical expenses that would be needed in December 2007 to reflect growth in the nonmedical component of the CPI-E. The last two columns show the percentage difference between columns (3) and (4), expressed relative to 
Table 3.2

Comparison of actual net-of-medical-care benefit and benefit needed to maintain ability to purchase nonmedical care bundle

\begin{tabular}{lccccc}
\hline $\begin{array}{l}\text { Cohort, age in } \\
\text { Dec. 2007 }\end{array}$ & $\begin{array}{c}\text { Benefit } \\
\text { at age 65 }\end{array}$ & $\begin{array}{c}\text { Dec. 2007, } \\
\text { actual }\end{array}$ & $\begin{array}{c}\text { Dec. 2007, } \\
\text { needed }\end{array}$ & $\begin{array}{c}\text { Percent } \\
\text { shortfall (\%) }\end{array}$ & $\begin{array}{c}\text { Percent increase } \\
\text { needed (\%) }\end{array}$ \\
\hline All men, 79 & 713.01 & 924.74 & 1028.93 & 10.1 & 11.3 \\
All men, 89 & 527.85 & 866.80 & 1086.13 & 20.2 & 25.3 \\
White men, 79 & 736.14 & 961.57 & 1062.30 & 9.5 & 10.5 \\
White men, 89 & 542.75 & 898.97 & 1116.79 & 19.5 & 24.2 \\
Black men, 79 & 598.75 & 763.91 & 864.04 & 11.6 & 13.1 \\
Black men, 89 & 448.92 & 729.05 & 923.73 & 21.1 & 26.7 \\
All women, 79 & 512.29 & 666.14 & 739.27 & 9.9 & 11.0 \\
All women, 89 & 456.05 & 682.57 & 938.40 & 27.3 & 37.5 \\
White women, 79 & 520.24 & 692.63 & 750.74 & 7.7 & 8.4 \\
White women, 89 & 468.49 & 700.76 & 963.99 & 27.3 & 37.6 \\
Black women, 79 & 511.09 & 626.16 & 737.54 & 15.1 & 17.8 \\
Black women, 89 & 406.75 & 670.33 & 836.95 & 19.9 & 24.9 \\
\hline
\end{tabular}

both the actual 2007 benefit ("Percent increase needed") and the 2007 benefit needed to keep up with inflation ("Percent shortfall").

For example, men born in 1918 have seen their average Social Security benefit, net of out-of-pocket medical expenses, rise from $\$ 527.85$ at the end of 1983 (at age sixty-five) to $\$ 866.80$ at the end of 2007 (at age eightynine). However, if this cohort's average benefit net of out-of-pocket medical expenses had kept pace with the nonmedical CPI-E over that time period, this amount would have been $\$ 1,086.13$ in 2007 . That is, the average benefit net of out-of-pocket medical expenses has declined by around 20 percent relative to the nonmedical CPI-E. Similarly, women born in 1918 have seen their average benefit net of out-of-pocket medical expenses decline by around 27 percent relative to the nonmedical CPI-E.

Table 3.3 shows the benefit net of average out-of-pocket medical expenses that retirees in both cohorts would be receiving in December 2007 if their benefits had been indexed to the CPI-E rather than the CPI-W. The last two columns, again, compare these amounts to the amounts that would be needed to offset inflation in nonmedical goods prices. This table suggests that retirees would have been more protected from inflation if cost-of-living adjustments had been based on the CPI-E. However, there is still a shortfall of 10 to 20 percent for the older cohort and 6 to 7 percent for the younger cohort. As noted previously, the reason indexing to the CPI-E does not fully compensate retirees for inflation is that, even if medical costs remained constant over time for the elderly, they tend to need additional medical care as they age, and the additional medical spending crowds out nonmedical spending. Thus, Social Security benefits net of average out-of-pocket medical expenses would tend to decline for each individual even if the price of 
Table 3.3

Comparison of CPI-E indexed net-of-medical-care benefit and benefit needed to maintain ability to purchase net-of-medical-care bundle

\begin{tabular}{lcccc}
\hline $\begin{array}{l}\text { Cohort, age in } \\
\text { Dec. 2007 }\end{array}$ & $\begin{array}{c}\text { Dec. 2007, indexed } \\
\text { with CPI-E }\end{array}$ & $\begin{array}{c}\text { Dec. 2007, } \\
\text { needed }\end{array}$ & $\begin{array}{c}\text { Percent } \\
\text { shortfall (\%) }\end{array}$ & $\begin{array}{c}\text { Percent increase } \\
\text { needed (\%) }\end{array}$ \\
\hline All men, 79 & 961.14 & 1028.93 & 6.6 & 7.1 \\
All men, 89 & 961.20 & 1086.13 & 11.5 & 13.0 \\
All women, 79 & 695.12 & 739.27 & 6.0 & 6.4 \\
All women, 89 & 768.45 & 938.40 & 18.1 & 22.1 \\
\hline
\end{tabular}

medical care rose at the same rate as the prices of other goods. This idea is illustrated graphically in figures 3.3 through 3.8 , in the contrast between the solid and dashed lines. A price index for medical care reflects the vertical shift over time in the solid line (the age profile of spending in any given year); it does not pick up the horizontal movement that occurs as an individual ages. In fact, each cohort is moving diagonally - to a higher curve as time passes, and to a point further to the right on that curve as its members age.

Because actual out-of-pocket medical expenditures are subject to a great deal of uncertainty, particular individuals may be more or less protected against inflation than shown here. We emphasize again that we are not claiming retirees are worse off than they were when they were sixty-five. Our analysis does not allow us to make any such utility comparisons. The CPI does not adequately account for the fact that higher medical costs may reflect the consumption of better quality medical care, and retirees may be better off even if they are left with less to spend on other nonmedical goods. All we have shown is that Social Security benefits may not be fully inflation-indexed in the sense that recipients cannot, from one year to the next, purchase the same bundle of nonmedical goods with their Social Security benefits.

\subsection{Policy Implications}

Our results suggest that retirees who depend primarily on Social Security have fallen behind substantially in terms of inflation-adjusted nonmedical spending. However, indexing Social Security benefits to the CPI-E-or alternatively, indexing benefits to keep real nonmedical spending constantwould clearly have an adverse impact on Social Security's finances.

To provide a back-of-the-envelope estimate of the impact on Social Security's finances, we begin with our estimates of the rate of increase in aggregate monthly benefit amounts required from 2006 to 2007 if (a) Social Security benefits had been indexed to the CPI-E, and (b) Social Security benefits had been adjusted to keep the real net-of-health benefit constant for the average retiree. We construct these estimates by using the number of retired workers in December 2006 and December 2007 by age and gender, 
actual average monthly benefits in December 2006 and December 2007 by age and gender, and our projections of average monthly benefits under scenarios (a) and (b). ${ }^{12}$

We find that aggregate benefits for individuals aged sixty-five to eightynine would have risen by 8.3 percent between December 2006 and December 2007 if benefits had been indexed to the CPI-E. Using the same methodology, if benefits had instead been adjusted to keep the real net-of-medical benefit constant, aggregate benefits for individuals aged sixty-five to eightynine would have risen by 12.4 percent over the same period. By contrast, actual aggregate benefits for this age group rose by only 5.6 percent between December 2006 and December 2007. ${ }^{13}$

The 2010 Social Security Trustees' report provides projections of the Old Age and Survivor's Insurance (OASI) program's income and cost rates through 2085. The income rate is defined as OASI tax revenue (from payroll taxes and taxation of benefits) as a percentage of taxable payroll, and the cost rate is defined as the cost of the OASI program as a percentage of taxable payroll. Using these income and cost rates, combined with the trustees' projections of gross domestic product (GDP) and taxable payroll as a fraction of GDP, we can project OASI's total income and costs through 2085. Under the trustees' projections of current law using intermediate assumptions, total OASI costs are projected to grow at an average rate of 5.6 percent per year between 2006 and 2085, in line with our estimate of the increase in aggregate benefits between 2006 and 2007. Consistent with our calculations for the growth in aggregate benefits between 2006 and 2007, we assume that indexation to the CPI-E would increase this growth rate by 2.6 percentage points in each year, and that indexation to maintain the real value of nonmedical spending would increase this growth rate by 6.7 percentage points in each year. ${ }^{14}$

Figure 3.11 depicts the income and cost rates of the OASI program under

12. Beneficiary counts by age and gender were obtained from the US Social Security Administration, Annual Statistical Supplement, 2008, Table 5.A.1, "Number and average monthly benefit, by type of benefit and race, December 2007," http://www.ssa.gov/policy/docs/statcomps/ supplement/2008/5a.html\#table5.al; and the US Social Security Administration, Annual Statistical Supplement, 2007, Table 5.A.1, "Number and average monthly benefit, by type of benefit and race, December 2006," http://www.ssa.gov/policy/docs/statcomps/supplement/2007/ 5a.html\#table5.a1.

13. The actual rate of increase between December 2006 and December 2007 is considerably larger than the rate of increase in the CPI-W during this time period of 2.3 percent. This discrepancy is due to the fact that the composition of beneficiaries also changes over time and, because of differential mortality by income, beneficiaries with lower Social Security benefits tend to die earlier than beneficiaries with higher Social Security benefits.

14. Our analysis of net-of-medical-cost spending uses only retired worker benefits, and applies only to workers between the ages of sixty-five and eighty-five. We compute estimates of the increase in the aggregate retired worker benefits paid to this age group under the status quo and alternative policies. Thus, our estimated growth rates for aggregate benefits are not strictly comparable to the trustees' estimates of OASI cost increases, as OASI costs include retired worker, spouse, and survivor benefits for individuals of all ages, as well as administrative 


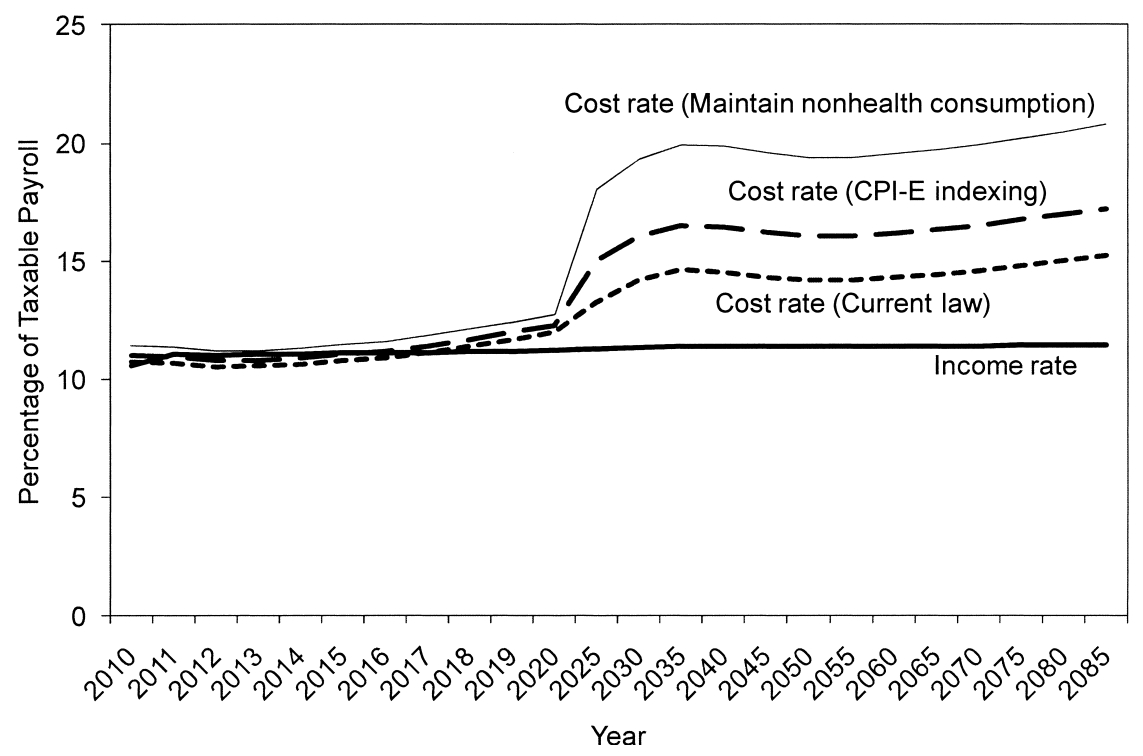

Fig. 3.11 Social Security income and cost rates as percentage of taxable payroll under alternative cost-of-living adjustments

current law, as well as the cost rate under each of these alternative indexing schemes, assuming the alternative indexing took effect in 2010. Under current law, persistent deficits begin in 2018. If benefits were indexed to the CPI-E, persistent deficits would begin two years earlier, in 2016, and if benefits were indexed to keep real nonmedical spending constant, persistent deficits would begin in 2015.

Starting with the assets of the OASI trust fund in 2009 (\$2.2 trillion), we project the trust fund assets under each of our alternative indexing schemes. For 2010 to 2019, we assume that assets in the OASI trust fund earn the interest rates implied by the Social Security Trustees' short-term intermediate projections of the OASI trust fund ratio and interest income. ${ }^{15}$ For 2020 and beyond, we assume that the interest rate paid on trust fund assets is 5.7 percent, which is the trustees' intermediate projection for the long-term nominal interest rate. ${ }^{16}$ Under current law, the OASI trust fund is projected to become exhausted in 2040. Exhaustion of the trust fund would occur five

costs. However, our back-of-the-envelope calculation assumes that the differences in the growth rates of aggregate costs across policies should be similar regardless of whether we look at retired worker benefits for workers aged sixty-five to eighty-five, or total OASI costs.

15. These projections are available in the US Social Security Administration, The 2010 OASDI Trustees' Report, Table IV.AI, "Operations of the OASI Trust Fund, Calendar Years 2005-19,”http://www.ssa.gov/OACT/TR/2010/IV_SRest.html\#280816.

16. See the US Social Security Administration, The 2010 OASDI Trustees' Report, Table V.B2, "Additional Economic Factors," http://www.ssa.gov/OACT/TR/2010/V_economic .html\#205214. 
to ten years earlier (between 2030 and 2035) if benefits were indexed to the CPI-E, and between ten and fifteen years earlier (between 2025 and 2030) if benefits were indexed to maintain the real value of nonmedical spending.

Given the state of Social Security's long-term finances, switching to one of these alternative indexing schemes is unrealistic from a policy perspective. While changes in benefits indexation can be done in ways that are revenueneutral (e.g., by reducing initial benefits and increasing the rate of increase), reforms of this nature would raise distributional concerns and would rely on the assumption that such a policy would be preferred to one where benefits indexation remained constant and beneficiaries utilized other savings vehicles to ensure the adequacy of benefits for later medical expenses. Social Security reform proposals generally take into account the need to protect low-income retirees from benefit cuts, and many proposals in fact increase benefits to low-income earners (e.g., National Commission on Fiscal Responsibility and Reform, 2010). In this spirit, it might be reasonable for policy makers to consider an alternative indexing scheme to protect very low-income retirees as part of a more comprehensive Social Security reform package.

\subsection{Conclusion}

We have shown that Social Security benefits may not be as safe from inflation as commonly believed. Because medical costs have been rising over time, and because the elderly spend a larger fraction of their income on medical care than workers do, the CPI-W does not properly reflect the inflation experience of Social Security beneficiaries. This is partly reflected in the fact that premiums for Medicare Part B, in which most retirees participate, have risen much faster than Social Security benefits. It is compounded by the fact that retirees often have substantial out-of-pocket medical expenses, which increase as they age. Even experimental measures like the CPI-E may not fully compensate for inflation because they are intended to reflect the inflation experience of the average elderly person from year to year, rather than the experience of a given cohort. Given the state of Social Security's finances, it would not be fiscally prudent to raise legislated benefits for all retirees to keep pace with the CPI-E or to maintain average real net-of-medical benefits. However, most Social Security reform proposals attempt to protect very low-income retirees, and the alternative indexing schemes discussed in this chapter can provide guidance on how to accomplish this goal.

\section{References}

Boskin, Michael J., and Michael D. Hurd. 1982. "Are Inflation Rates Different for the Elderly?” NBER Working Paper no. 0943. Cambridge, MA: National Bureau of Economic Research, February. 
Burdick, Clark, and Lynn Fisher. 2007. "Social Security Cost-of-Living Adjustments and the Consumer Price Index." Social Security Bulletin 67 (3): 73-88.

Cristia, Julian P. 2007. "The Empirical Relationship between Lifetime Earnings and Mortality." CBO Working Paper 2007-11. Washington, DC: Congressional Budget Office.

Di Nardi, Mariacristina, Eric French, and John Bailey Jones. 2009. "Why Do the Elderly Save? The Role of Medical Expenses.” NBER Working Paper no. 15149. Cambridge, MA: National Bureau of Economic Research, July.

French, Eric, and John Bailey Jones. 2004. "On the Dynamics and Distribution of Health Care Costs.” Journal of Applied Econometrics 19 (6): 705-21.

Hobijn, Bart, and David Lagakos. 2003. "Social Security and the Consumer Price Index for the Elderly." Current Issues in Economics and Finance 9 (5): 1-7.

List, Matthew Patrick. 2005. "Inflation and the Elderly." Unpublished Manuscript. Boston College, Chestnut Hill, MA.

National Commission on Fiscal Responsibility and Reform. 2010. "The Moment of Truth: Report of the National Commission on Fiscal Responsibility and Reform." Washington, DC: National Commission on Fiscal Responsibility and Reform. http://www.fiscalcommission.gov/sites/fiscalcommission.gov/files/documents/ TheMomentofTruth12_1_2010.pdf.

Stewart, Kenneth J. 2008. "The Experimental Consumer Price Index for Elderly Americans (CPI-E): 1982-2007.” Monthly Labor Review 131 (4): 19-24.

Waldron, Hilary. 2007. "Trends in Mortality Differentials and Life Expectancy for Male Social Security-Covered Workers, by Socioeconomic Status." Social Security Bulletin 67 (3): 1-28.

\section{Comment Michael D. Hurd}

In the mid-1980s Boskin and Hurd calculated a separate Laspeyres price index for the older population using weights that reflected the different consumption pattern by the older population (Boskin and Hurd 1985). Of particular interest was the higher budget share for health care (fraction of total spending for health care): in the population less than age sixty the budget share was 4.9 percent, whereas in the population age seventy-five or older it was 9.8 percent. A higher rate of inflation for health care services interacted with a greater weight on them would result in a higher inflation index for the older population. However, Hurd and Boskin found that "the inflation experience of the elderly from 1961-1981 was quite similar to the general population both cumulatively and year-by-year." Table 3C.1 gives their prices levels in 1961 and 1981 by age group, and, indeed, the cumulative price increases are almost identical across the age groups. One reason for this somewhat surprising outcome is that the rate of inflation for health

Michael D. Hurd is principal senior researcher and director of the Center for the Study of Aging at the RAND Corporation, a research fellow of NETSPAR, and a research associate of the National Bureau of Economic Research.

For acknowledgments, sources of research support, and disclosure of the author's material financial relationships, if any, please see http://www.nber.org/chapters/c12434.ack. 